\title{
Insights and reflections using data analytics approach of COVID- 19 situation among the Indian states and ethical considerations
}

\author{
Zairu Nisha ${ }^{1} \cdot$ Sachin Kumar $^{2}$ (I) $\cdot$ Saibal K. Pal $^{3} \cdot$ Jagvinder Singh $^{4} \cdot$ \\ Ompal Singh ${ }^{5}$
}

Received: 21 May 2020/Revised: 3 May 2021/Accepted: 23 May 2021/Published online: 2 June 2021

(C) The Society for Reliability Engineering, Quality and Operations Management (SREQOM), India and The Division of Operation and Maintenance, Lulea University of Technology, Sweden 2021

\begin{abstract}
COVID-19, a pandemic has suddenly created an unprecedented crisis in the world. COVID-19 has severely affected the lives of all the people around the world by forcing the closure or suspension of almost all socio-economic activities. Some of the countries including developed and developing such as China, the USA, Italy, Spain, the UK, France, Iran and India, etc are comprehensively affected to a deep level by this virus in terms of an incurable disease. Several countries have no options as they were hit by COVID-19 in total surprise and had no case study to follow. But some countries have attempted to face the virus such as China, Italy, Spain, Iran, etc. In this context, India has strict preventive majors in the form of a lockdown strategy besides the loosely executed testing and
\end{abstract}

Sachin Kumar

official.sachin@gmail.com; skumar@cic.du.ac.in

Zairu Nisha

zairunisha@gmail.com

Saibal K. Pal

skptech@yahoo.com

Jagvinder Singh

jagvinder.singh@gmail.com

Ompal Singh

drompalsingh1@gmail.com

1 Ramanujan College, University of Delhi, Delhi, India

2 Cluster Innovation Centre, University of Delhi, Delhi, India

3 Defence Research and Development Organisation, Delhi, India

4 School of Management and Entrepreneurship, Delhi Technological University, Delhi, India

5 Department of Operation Research, University of Delhi, Delhi, India tracking methods. Despite all policies and decisions implementation, and their stringent execution, it is spread, and now India is in the top three COVID-19 affected countries. The rampant increase of COVID-19 cases, their response, and its impact on mortality, the effectiveness of controlling the situation by States need sharp analysis. The proposed work is an attempt to critically assess and explore the pervasive pandemic situation spread in most of the Indian state utilizing comparative analysis using data science methods contrasting them horizontally. Furthermore, the research work suggests few in-depth insights and recommends directions, steps for the public, government and other stakeholders for better management of the COVID-19 situation. Additionally, the study also deals with some ethical issues involved in the data creation, curation, and reporting on the various platforms used in the research work.

Keywords COVID-19 - Data science - Comparative analysis · Insights $\cdot$ Ethical considerations

\section{Introduction}

COVID-19 is a pandemic; a disease affecting the whole world from small to large extent country after country. The first case of novel virus infection from COVID-19 was reported in China, Wuhan province in December, 2019 (Hui et al. 2019). Since then, it has spread in Europe, the USA, and Asian and Latin American Countries. COVID19's induced situation became extremely threatening and WHO declared COVID-19 a world health emergency on 13th March, 2020 (World Health Organization et al 2020). Countries such as China, Italy, UK, Spain and Iran were 
observed to be badly affected in February and early March 2020. Although In India, the first case of the COVID-19 was reported from Kerala, a southern state in the last of December 2019, the Indian government and its administration could not prepare a plan and strategy for COVID-19 till March 2020. Consequently, the Indian government decided suddenly to impose a severe and stringent lockdown on 25th March to contain the spread of the virus and break the transmission and infection chain 2020 (Sinha and Sinha 2020). There have been two observations on COVID-19 and its unstoppable infection transmission and adopted measures across the world imposing lockdown. Firstly, there has been no cure for the virus. Although scientists and researchers are working day and night to find the cure for COVID-19 in the form of vaccines. Secondly, the only way to stop the transmission of the virus is to keep a safe distance from the other person. Hence, Countries in a desperate attempt to save lives and control the COVID-19 transmission preferred the lockdown approach. Simultaneously, the administration also pushed for extensive testing of the patient through contact tracing and of those showing the symptoms of COVID-19 such as high fever, coughing, body pain etc (Cohen and Kupferschmidt 2020). The Indian government has also strictly imposed the restriction of going outside except for essential services such as food, health, law and order, and National Security Services. Due to the nature of the economy and its impact on the life of people due to the suspension of economic activities. The International Monetary Fund (IMF) and other international policy institutions have expressed great concerns regarding the job losses and contraction of the gross domestic product (GDP) of the world economy (Fernandes 2020). Few countries may be hard hit. Furthermore, few countries may go into recession and their socio-economic systems may collapse. Although it is quite clear that the economies in Europe, the USA, China, India, Japan, and Singapore are badly hit from COVID-19 (Loayza and Pennings 2020). COVID-19 has wide implications starting from economic issues such as unemployment, job losses, salary reduction, etc to personal, ethical and psychological issues about life and the future. It is not wrong to say that post corona's big implications and consequences may force us to change and adapt to the new lifestyle across the world which is sustainable for the present generation and for the future generation. Thus, India's COVID-19 situation needs detailed and thorough investigation and assessment at the state level. India is the second-largest country in terms of population, sixth largest in terms of purchasing power parity (PPP) (Mathur 2020) due to this demographic conditioning, India reported the first covid positive case in Kerala in January, whereas the rest of the country was doing well. The Indian government also observed and witnessed the severity of the situation in other affected countries which gave the policymakers and administration at least two weeks extra time to prepare and to respond effectively. The study has incorporated all the considerations to provide a wide spectrum. Following are the questions which have been addressed and discussed in depth.

1. Discussion on initiation and growth analysis of the pandemic COVID-19 in India.

2. Analysis of growth rate, fatality and recovery rate and death state wise.

3. Analysis of test-related statistics such as testing rate, infection cases, confirmed cases state wise.

4. COVID-19 transmission cases, their trends and analysis state wise.

5. Insights and recommendation for policymakers and administrators.

6. Discussion some of the ethical issues related to the data quality and data collection methods.

With this line of thought, the present paper is organised in the following manner; the first section presents the introduction. Section 2 deals with the literature survey. Section 3 explains the research methodology. Section 4 presents results and analysis. Section 5 presents insights and recommendations and Section 7 concludes the study.

\section{Literature survey}

An unprecedented situation posed by COVID-19 has forced not only the general public but also the scientific community, policymakers and decision-makers to think seriously and get the insights and directions based on objectivity, rationality keeping in mind the welfare of the state and the lives of people at large. Several studies have been conducted to have scientific opinion-based decision making addressing several dimensions of the COVID-19 scenario. Emanuel et al. (2020) have focused on medical resource availability and fair resource allocation. Alhazzani et al. (2020) have addressed the decision making processes and recommended some guidelines for critically ill adults to save their life and better health care. At present the real-time situation is changing rapidly, country by country are coming into the grip (Del Rio and Malani 2020). Each country has some specific characteristics depending on its population, demographic profile, geographic location, cultural aspects and development patterns. Hence the impact of COVID-19 and its intensity varies. Rodriguez-Morales et al. (2020) analysed Latin American cases with implications after the first reporting of the case in Brazil. Similarly, Gilbert et al. (2020) conducted a preparedness and vulnerability analysis of African countries. It is quite evident that COVID-19 is a new 
phenomenon and no sufficient past data is available related to a pandemic with countries which they could use for their benefit and for future course of actions. As researchers were able to get the enough data to detect the COVID-19 though many advanced and latest technological developments such as AI and Machine Learning conducted experiments and presented the results to the scientific community in order to assist the decision making. Data science, Artificial Intelligence and Machine Learning have been used in many diverse fields earlier also rapidly growing and having an impact on daily life. For instance, AI have been used in the development of smart cities, energy prediction tool (Kumar et al. 2018a; Kumar and Singh 2019), intelligent transportation, especially in accident detection system (Kumar et al. 2017) and intelligent health management systems (Kumar et al. 2018b). In the COVID-19 context, researchers from China have analysed the available cases, especially in a city as Wuhan and identified some correlation of chest CT and RT-PCR testing (Ai et al. 2019). Taiwan also employed technological solutions such as data sciences, big data for better insights into the COVID-19 cases (Jason Wang et al. 2020). Arentz et al. (2020) analysed characteristics and outcomes of ill patients in Washington state and provided useful insights. Cascella et al. (2020) put forward the assessment, analysis of the treatment process of COVID-19 patients. Several studies have also been conducted to understand the patterns and trends of COVID-19 crises for course correction and proper decision making. Paquet and Schertzer (2020) discussed the COVID-19 situation as a complex Intergovernmental issue due to its pandemic nature, globalised world and cooperative and competitive decision making. Pandemic COVID-19 has many dimensions encompassing the environmental, socio-economic, ethical and political. de Paz et al. (2020) highlighted the gender dimensions of the COVID-19 pandemic. Wang et al analyse the policy of COVID-19 pandemic lockdown imposed in Chinese cities and homestay policy and its effect on COVID-19 (Wang et al. 2020). In a similar manner, Dong et al. (2020) gave a validation study for successful policy in China through meta-analysis. Lockdown has imposed restrictions on economic activities and only essential services are allowed, Mhlanga and Ndhlovu (2020) assess the Socio-economic Implications of the COVID-19 Pandemic on Livelihoods in Zimbabwe. Similarly, several studies have quantified the macroeconomic implications of COVID-19 lockdown (Mihailov et al 2020). Taking the case of India, COVID-19 and subsequent measures taken, Rajagopalan and Choutagunta (202) provided a detailed assessment of healthcare facilities and capacity in India. Vijayaraghavan and Singhal (2020) presented a comprehensive study of Indian citizens' psychological responses to COVID-19 under pandemic stringent lockdown. Lockdown due to COVID-
19 has many unintended consequences such as the reduction in emission in Indian metropolitan cities, depression, lack of economic resources, premature death etc. Sharma et al. (2020) studied the effects of lockdown and its restricted emissions during COVID-19 on air quality. Gabay et al. (2020) analysed public compliance with social distancing in India. Singh and Adhikari (2020) attributed their study to analyse the impact of age on the spread, fatality, death rate and recovery in India. Samui et al. (2020) have presented a mathematical model to understand and get an insight into the COVID-19 transmission in india. Khajanchi and Sarkar (2020) worked on the forecasting of the daily and cumulative number of infections for the COVID-19. Venkateswaran and Damani (2020) assessed the effectiveness of testing, teaching and social distancing in the tracking in India and proposed a system dynamics model. Sarkar et al. (2020) also designed a model to predict the COVID-19 in Indian circumstances. Khajanchi et al. (2020) provided the dynamics of the COVID-19 pandemic in India. Observing all work done in international share and Indian domain, State-wise strategy and their patterns and gaps have not been explored by the scientific community till now. There is a lot of gap in several dimensions of the impact and assessment of COVID-19 situations in India and other states. There is no study to highlight the insights about the State-wise situation, their problems and government responses. This study addresses those gaps and puts forward the insights and recommendations based on Inter-State comparison of COVID-19 based on many trends and parameters such as morality, health infrastructure, geographic locations and their impact on their impact due to COVID-19.

\section{Research methodology}

The research work primarily focuses on the Indian COVID19 scenario. India is known as a subcontinent encompassing a high level of diversity. It includes the diversity of religion, diversity of geographic and physical features, diversity of languages and dialects and one of the most important is the diversity of homogeneous and heterogeneous cultural and tradition in communities. Politically and administratively, It has been divided into political units for governance and these parts are called States and Union Territories (UT). Indian constitution provided for the division of power between union and state government by listing the subjects of governance into three lists. These lists are central list, state list and concurrent list defining the working and policymaking space for centre and state. States and central governments having their own administrative heads have taken decisions that were mainly executed by states. The COVID-19 situation including the 
spread, fatality rate need thorough investigation under various parameters states wise. To answer the questions set under the light of the research objective of the study. What is the impact of their decisions, outcomes on COVID-19 situations and associated parameters such as infection rate, fatality rate, recovery rate etc needs deep analysis? This study takes a stream of data being updated on a central database state-wise and UTs wise on the parameters such as fatality rate, recovery rate, infection rate, population, health issues, infections cases, geographic locations, administrative arrangements done by states and accountable administration and development index. All these parameters taken in the form of data have been compared through data analytics tools to get useful patterns and insights. The basis of the study is to compare the actions, outcomes and situations of COVID1-9 on the basis of states and their comparative analysis, keeping states on the horizontal axis. Hence in the study, we call it horizontal analysis of the COVID-19 situation in India. More specifically, it provides insights and reports the gaps in the execution and outcomes in a particular state in comparison to other states. There are several data sources that have been merged to prepare a central database to analyse the COVID-19 scenarios in India. Data has been taken from the World health organisation(WHO) web source, John Hopkins University web source, European Union website, Indian official government web source (www.mygov.in) and www.covid-19india.org (Mygov WHO 2020). Collected data was cleaned for few missing values and collated together to get the state wise scenario. Using the data analytics approach, bar charts and multiple bar charts have been presented as visualisation tools. The presented analysis is both quantitative and qualitative. Quantitative analysis and discussion include quantitative results obtained from state-wise comparison on COVID-19 cases and population and health infrastructure criteria and doing time series analysis of the growth of COVID-19 cases in the Indian context. Qualitative analysis is presented in the discussion with the state of the health situation, immigration situation, development and growth subjective understanding state wise. The present study does not intend to model and predict the cases on COVID-19 using mathematical modelling. More importantly, the study follows a time-series pattern of events to analyse them and the spread of the COVID-19 in Indian states and their responses, approaches used by different states and their effectiveness and efficiency in containing the virus spread and infections.

\section{Result and discussion}

Research methodology and data visualisation tools provided directions to get insights and deep horizontal analysis of the COVID-19 situation in Indian states wise. All states and UTs have been compared on several important and relevant parameters to assess the performance and efficiency of states (having some level of autonomous decision making) in monitoring and mitigation of COVID-19 infection transmission, mortality and recovery patterns and trends. Additionally, states weaknesses and advantages have also been incorporated in the result discussions. Moreover, some demographic related data have been made the foundation to reason and support the claims as obtained and observed through data analysis. This makes better sense and gets a deep insight into the prevailing situation to make objective, rational and reliable recommendations. Figure 1 represents the time series of the COVID-19 cases reported in India in all the states and UTs starting from 25th March to 2020 to 25th April 2020, for a one-month duration. Carefully observing the plot signifies that the death rate is very less in comparison to the transmission of the COVID-19. After 25th April, COVID-19's transmission has sped up exponentially. The recovery rate is quite good. In this plot, it is observed that although initial COVID-19 cases were reported in the state, Kerala. But the number of the cases were very small by mid of April 2020. India has not seen the exponential growth of the cases or the community transmission as expected by many researchers in the predictions till the mid-week. This has been the result of stringent lockdown which stops the movement of human beings working as vectors for spreading the COVID-19. The good recovery rate has been attributed to the lifestyle of Indians and BCG vaccination in the 1960 s by researchers to ensure a better immunity of the virus in the Indian population (Shivendu et al. 2020). Figure 2: gives insights about the trends and patterns of COVID-19 transmission growth in all States and UTs. The plot displays COVID-19's fatality, growth rate and recovery rate state wise. The fatality rate is high in Telangana, Andhra Pradesh, Delhi, Gujarat, Himachal, Jharkhand, Karnataka, Madhya Pradesh, Maharashtra, Meghalaya, Punjab, Rajasthan, Tamilnadu, West Bengal etc. The growth rate is high in Andhra Pradesh, Bihar, Delhi, Gujarat, Haryana, Jharkhand, Karnataka, Madhya Pradesh, Maharashtra, Odisha, Punjab, Rajasthan, Tamil Nadu, Uttarakhand, Uttar Pradesh, West Bengal and Andaman Nicobar. The recovery rate is higher in all the states. Importantly, the recovery rate is highest in states which are situated in a remote area with hilly environments and less population. This may be due to those areas where physical life is difficult which forces the cities to do physical work 
Fig. 1 The figure depicts the COVID-19 growth trends in India from March, 2020 on four type of COVID-19 cases:

Confirmed COVID-19 cases,

Recovered COVID-19 cases,

Death due to COVID-19 and active COVID-19 cases
Total covid-19 cases time series combined with all states

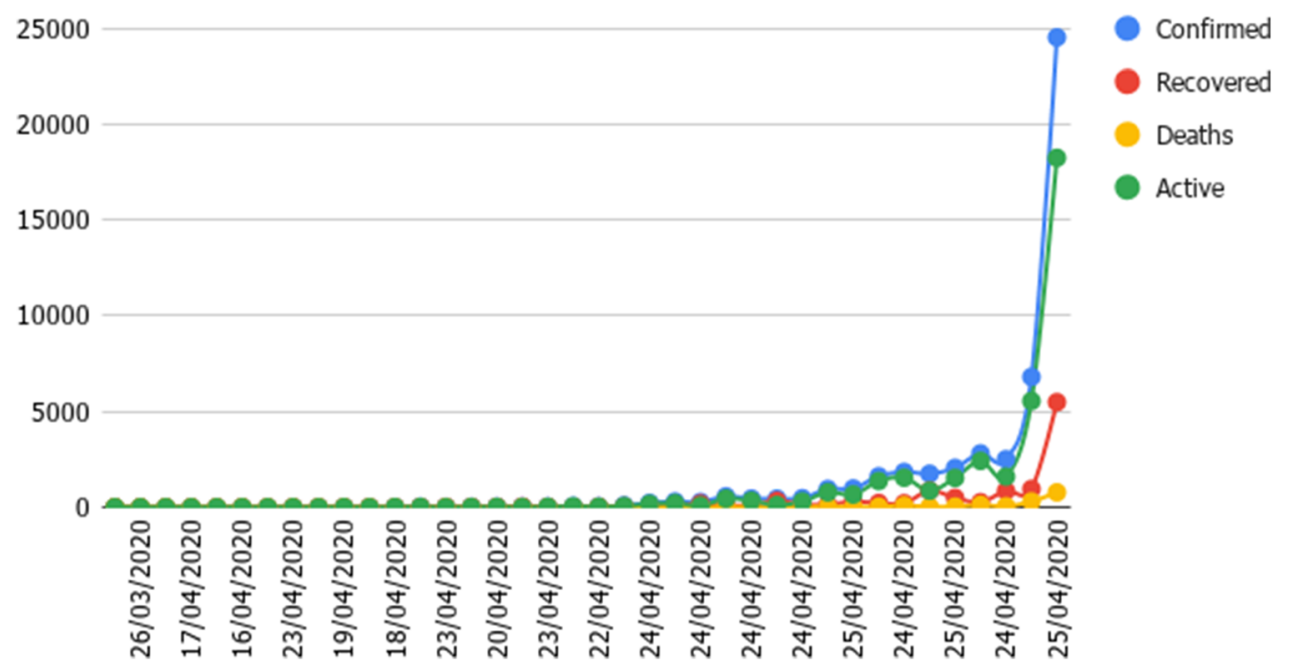

State wise growth, fatality and recovered rate

GROWTH RATE \% FATALITY RATE \% RECOVERED RATE \%

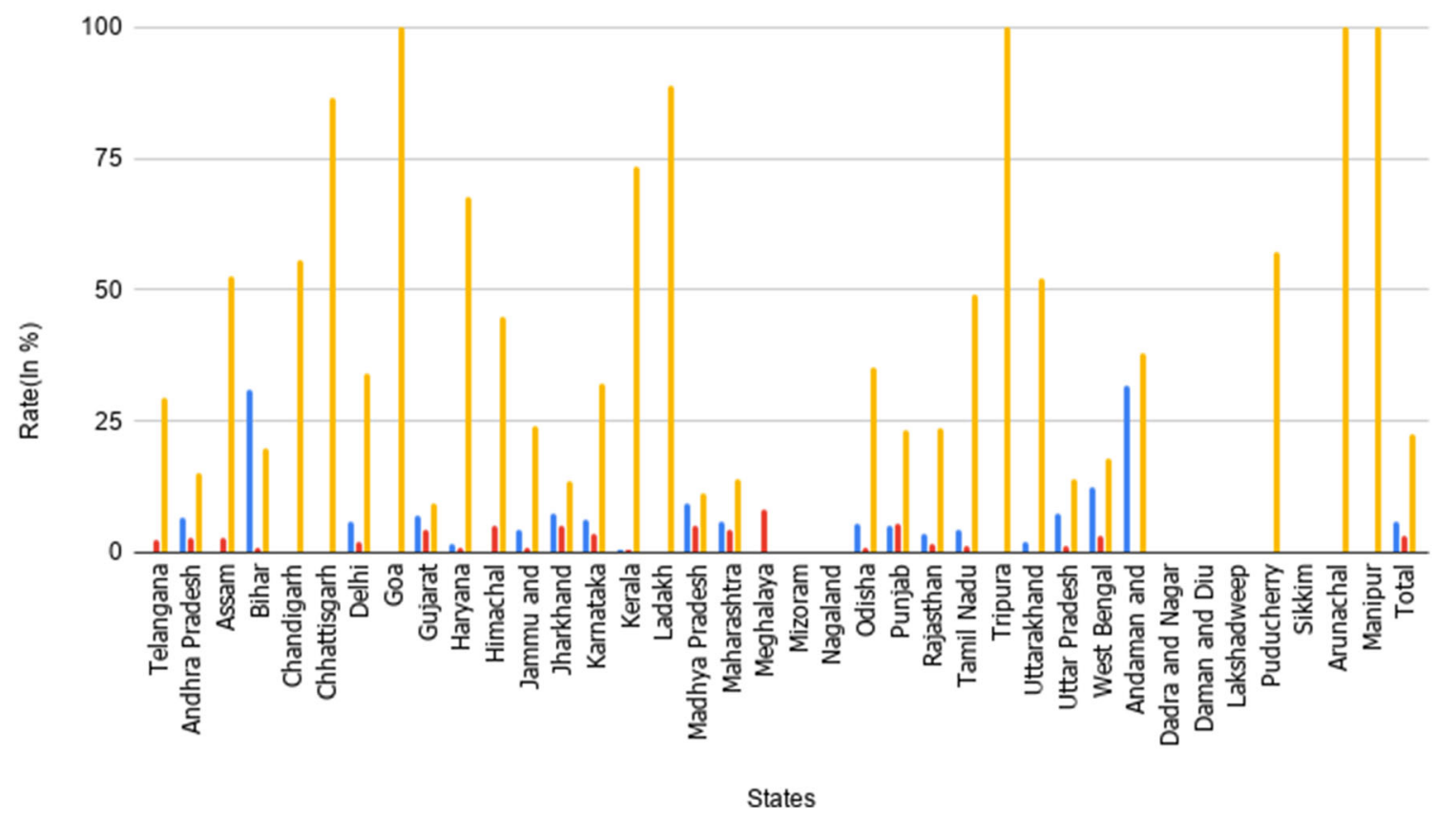

Fig. 2 Figure depicts the trends of COVID-19 growth rate in percentage, Fatality rate in percentage, Recovered rate in percentage and compare them among States and UTs Horizontally

and improve their physical strength and immunity. In contrast to this, states such as Delhi, Maharashtra, Karnataka etc with more advanced development and more population density are suffering more with high fatality and COVID-19 growth. In India, not all the states and UTs are industrialized as the development process is lopsided. Some of the states and UTs are India's engines of economic growth with development and growth in industry and service sectors. Other states such as Uttar Pradesh and Bihar have a large population seeking employment. These states labour goose to industrialised states making them migrant labourers. In this context, from the plot, it is observed that states and UTs such as Uttar Pradesh and Bihar in the beginning, contributing labourers are less affected by COVID-19. Additionally, states such as Delhi, Maharashtra, Karnataka having more advanced 
transportation, industrialization and inward labour movements or migration are more COVID-19 affected and more prone to the spread of COVID-19. The industrialised States and UTs including NCT Delhi, Maharashtra, Gujarat, Karnataka. One more reason for having been affected more by COVID-19 is the international connectivity. It has been stated by many sources that testing cases are very low in India. India would have been in a better position if they would have proactively identified the traveller and cases at the airport as India has two weeks advanced observation time of what was going on in the world, especially in badly hit COVID-19 countries such as China, Italy, Iran and Spain. States having difficult terrain and geography such as Himalayan states and North-East states are better equipped due to less population, less possibility of personal contact and movement and people's social distancing behaviour. Figure 3 displays the patterns of Indian States and UTs in comparison of number of deaths, recovery rate and number of days of hospitalisation due to COVID-19. Recovery per death is highest in Kerala, followed by Haryana, Odisha, Tamil Nadu, J\&K, Rajasthan and Telangana. In Delhi, it is as good although the health facilities are better as compared to other states and UTs. Why is Delhi suffering more? There may be many reasons. International flights and commuting citizens, densely populated UTs and high levels of population in most of the time of year. Pollution reduced immunity and reduced up to 5 years of life. Recovery per death tells that more people recover and fewer are dying after the infection. Haryana is a considered physically healthy State of India due to its food habits and physical strengths and farming occupation. The best recovery rate is in the Himalayan States such as Uttrakhand, Jammu and Kashmir, Himachal Pradesh and northeastern states as compared to states having plain geography. States having plain geography and falling in between the Yamuna and the Ganga have huge populations, high levels of water and air pollution, lack of health cards and educational facilities due to a high degree of competition with fewer resources and corruption. The highest days of hospitalisation have been observed in the Ladakh region due to the extreme weather of the region. In most of the States and UTs, the hospitalisation days are similar that is from 10 days to 15 days. Figure 4 presents the growth of COVID-19 infections in terms of the rate of doubling day wise. More clearly, it is the number of days in doubling the number of COVID-19 cases. This is a very important parameter. During the linear growth, this parameter is less but as the growth rate takes the shape of the exponential function, it reduced drastically. This happens during the community transmission stage when there is no control on the contact tracing and infection transmission and the only way left is to upgrade the health infrastructure and respond to the uncontrollable situation. To prevent this situation, Lockdown has been proposed and implemented. The plot gives the impression that the doubling rate is high in Delhi, Gujarat, Maharashtra, Tamil

\section{State wise comparison of deaths, recovery and hospitalization}

\section{RECOVERY PER DEATH RECOVERED RATE \% AVG. DAYS OF HOSPITALIZATION}

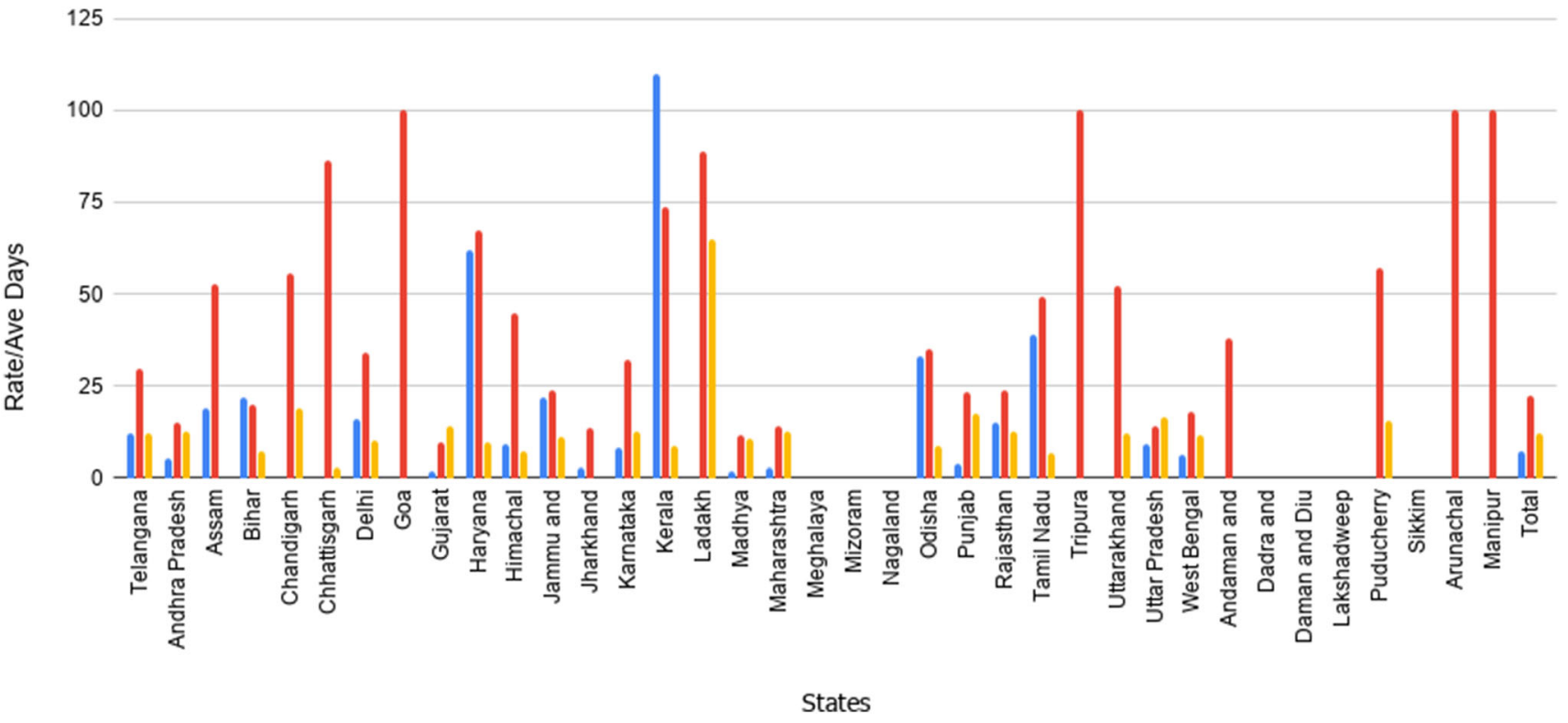

Fig. 3 Figure depicts the trends of COVID-19 recovery per death, recovered rate in percentage and number of days of hospitalisation and compare them among States and UTs Horizontally 


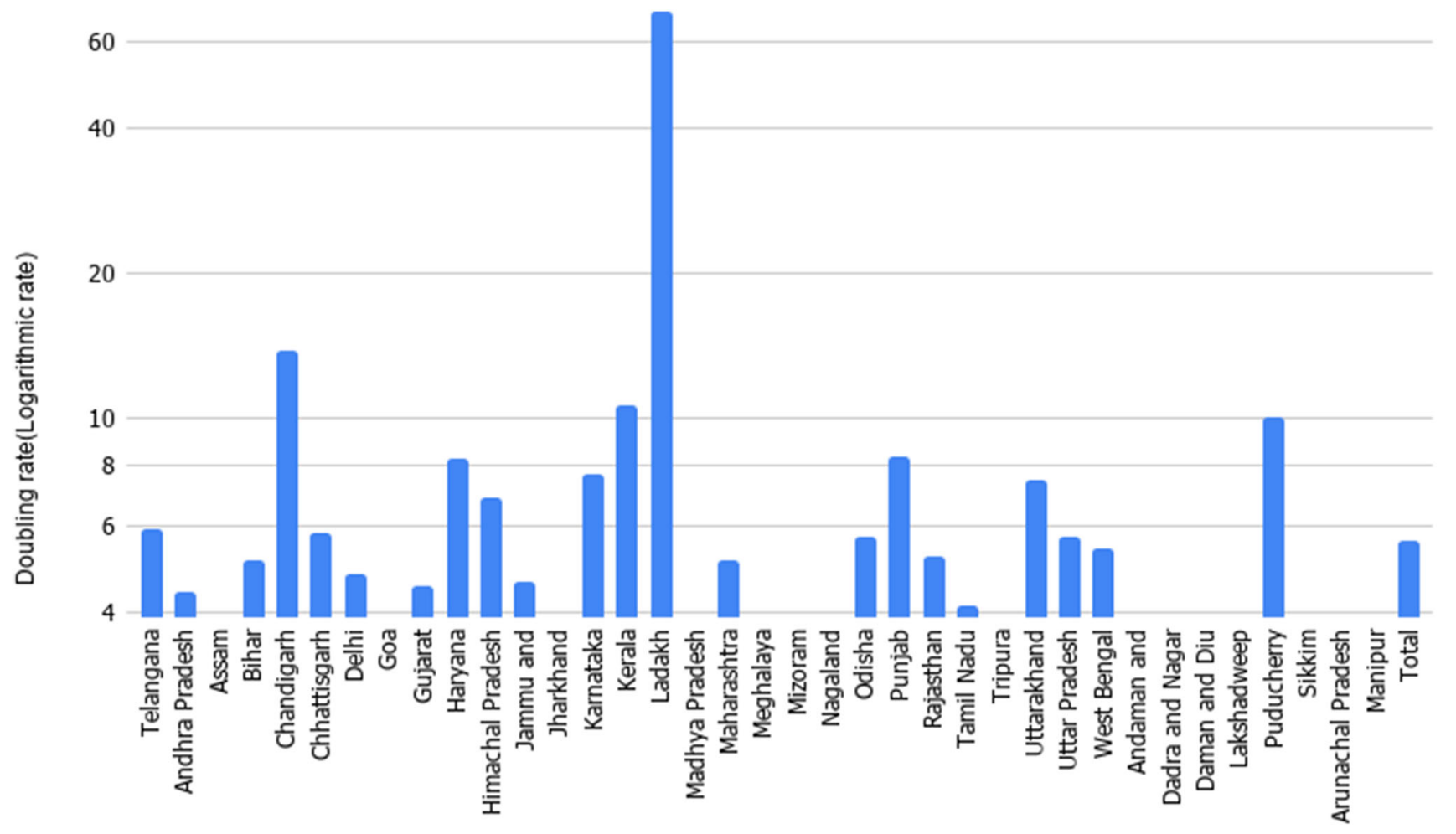

Fig. 4 Figure depicts the trends of COVID-19 doubling rate (number of days taken in doubling of active COVID-19 cases) and compare them among States and UTs Horizontally. Data is plotted in logarithmic scale

Nadu and Andhra Pradesh. All these states have substantial levels of industrialisation and migration from other states. These states also have more urbanisation as compared to the other states which have shown a low doubling rate due to their difficult terrain and less economic development. Such observations have inferred that more industrialised and urbanised regions must have better health and residential services to avoid the disease. States which are geographically difficult are better at having a high doubling rate. Here regional planning may also come into the picture if the case of Chandigarh is taken which has quite a high doubling rate and the city is a well developed and urban region of the State, Punjab.

Figure 5 puts forward the trends of the testing strategy and methods adopted by each State and UT. The figure compares states and UTs on tests per million, positive cases per million and per cent of confirmed over total tests. It is observed and reported in international media that India's testing rate is very less as compared to other countries taking into consideration its population (IANS 2020). It is even less than that of Pakistan (Mygov WHO 2020). The testing rate measures the number of COVID-19 test cases conducted per million population. In India, Delhi is leading in terms of number of tests per million cases. Delhi is considered a good state in terms of health facilities due to the priority of the Delhi government which has allocated approximately 20 per cent of the economic budget to health and introduced several acclaimed new health facilities and schemes such as new hospitals and decentralisation of health facilities through PolyClinic and Mohalla Clinic. This is one of the reasons for having more cases as more testing is being done. This is reflected in reporting of positive cases as that number is also higher in Delhi. The other States and UTs are facing a problem of lack of testing kits and lack of trained health professionals (Shekhar 2020). They are more focused on stringent lockdown imposition strategies and social distancing. Although, it seems that Lockdown is not the final answer. As soon as the lockdown is lifted and people having COVID-19 cases which are also asymptomatics start travelling, COVID-19 infections will spread in the second wave. Experts report that second waves of COVID-19 may be more fatal than this phase. So more testing must be done and more resources should be allocated to contain the spread and stop the community transmission stage. Figure 6 compares the results of the several states and UTs on four very important points related to COVID-19. Four parameters are the percentage share of states and UTs in total COVID-19 infections/cases, the share of states and UTs in total COVID-19 active cases, the share of states and UTs in total COVID-19 death cases, the share of states and UTs in COVID-19 tests. From the plot it is clear that the 
State wise test statistics

TESTS PER MILLION DOSITIVE CASES PER MILLION \% OF CONFIRMED OVER TOTAL TESTS

2500

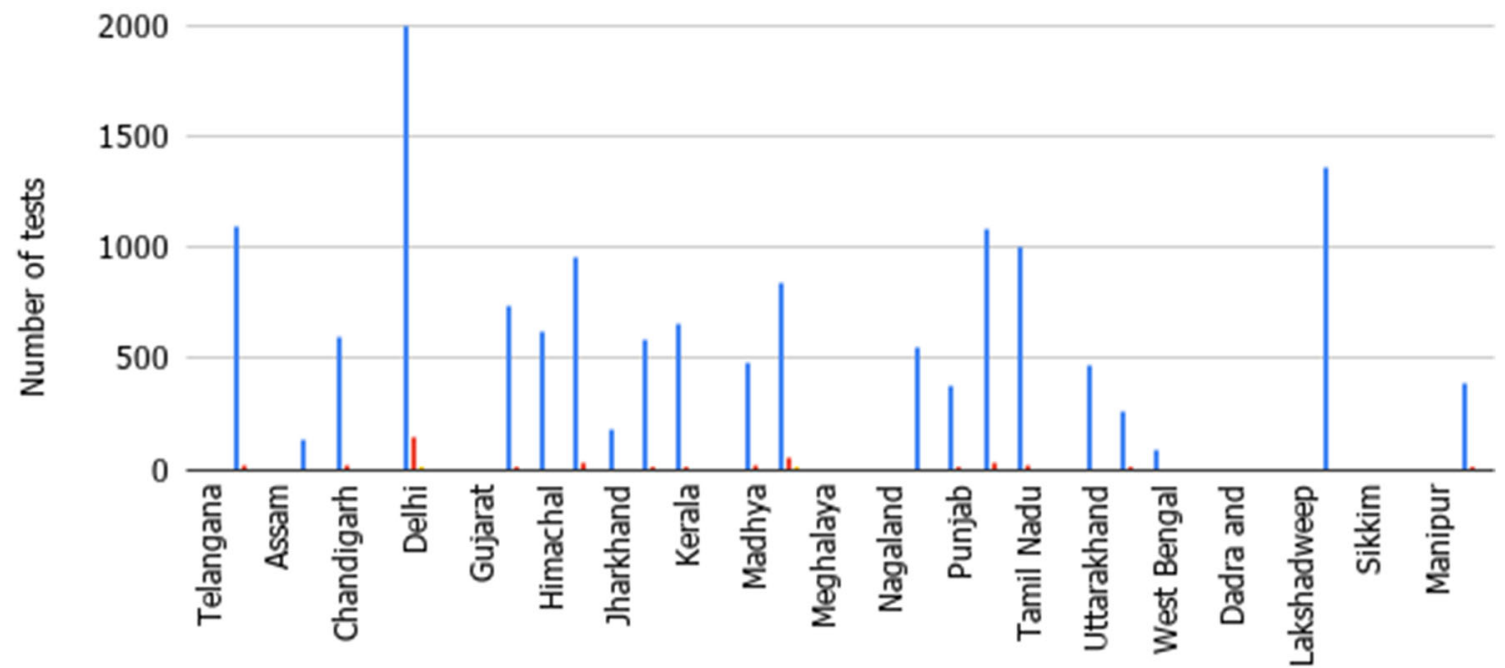

States

Fig. 5 Figure depicts the trends of COVID-19 test patterns and statistics and compare them among States and UTs horizontally

share of the rate of mortality and share COVID-19 death cases is highest in Maharashtra, followed by Gujarat and Delhi and Madhya Pradesh(MP). Interestingly, Each of the states and UTs has different reasons for the spread of COVID-19 and death due to COVID-19. Maharashtra and Gujarat follow similar trends and reasons for COVID-19 as both of them have an almost similar level of industrialisation and urbanisation. Decision making has been in confusion due to change in the administration and political authority. This situation forced the delay in active decision making in MP. Specifically, the top level of bureaucracy also suffered from COVID-19 and their health workers of top-level also faced similar problems forcing them and the system to complete breakdown. NCT Delhi has been able to manage its death rate to thirty due to the proactive testing rate and proactive measures taken by the government and volunteers. The figure depicts that the deaths are mostly in these four states and UTs. Another observed situation from our data visualisation is that in states like Gujarat and Maharashtra, their rate of testing is not near the satisfactory level. Good testing rate of COVID-19 helps in better health care provisions, mitigation and recovery than the lack of test cases which only contributes to more virus spread but also increases the mortality rate. In the case of the share of the COVID-19 cases, Maharashtra and Gujarat are leading followed by Delhi and Maharashtra. This is depicted in Fig. 7, also with state and UTs wise map of India. The reasons again are the same as States have more congested living and lack of health and other facilities for migrant workers from other poor states, part of the country. There is an interesting note here that there is no or very few active cases of COVID-19 in Chhattisgarh, Goa, Mizoram, Nagaland Meghalaya, Ladakh, Tripura, Uttarakhand, Pondicherry and Sikkim etc. All these states either have better life expectancy and immunity or better way of living and also better education and awareness about the issues. These states are also from mountainous regions.

\section{Insights and recommendations}

After discussion and critical analysis of the results, this section suggests some measures which are better for decision making and administration for government officials and policymaking. States which are doing good are NCT Delhi and other remote areas such as the Himalayan States and Northeastern states including Kerala and Goa. Other states need to learn from their strategies, especially political and administrative decision making. Lockdown is a good measure but not a sufficient measure. Lockdown needs the support of extensive testing support to ensure the tracing and quarantine of affected persons. Imposing 
States comparison on covid-19 cases

$\%$ OF TOTAL CASES STATES SHARE $\square$ OF ACTIVE CASES STATES SHARE $\quad \%$ OF DEATH CASES STATES SHARE $\quad \%$ OF TESTS STATES SHARE

40

30

20

|

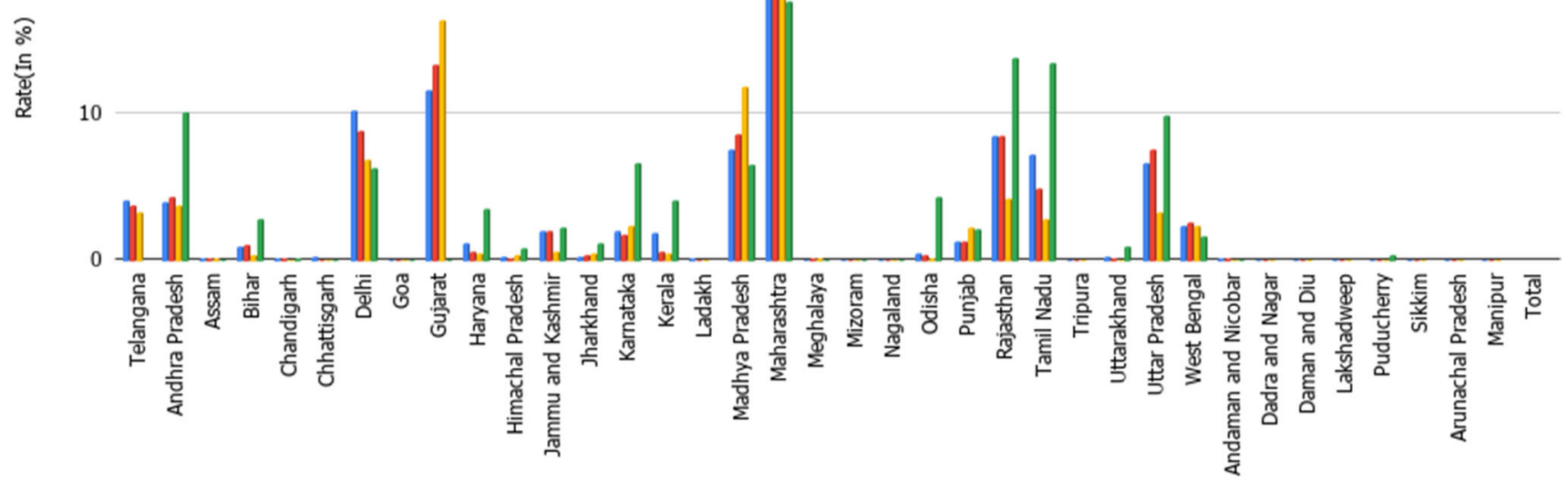

States

Fig. 6 Figure depicts the trends of COVID-19 percentage of state in total cases, percentage of state in active cases, percentage share of death cases and percentage share of test cases and compare them among States and UTs horizontally

lockdown for a longer period will surely have a bad impact on the large population of this country, especially on poor people, daily wages earners, farmers and small shopkeepers as they don't have enough food and money to support their livelihood. District wise strategy should be adopted and locking of districts with clear and unambiguous guidelines keeping future circumstances and situations in mind, needs to be followed. Better educated states and UTs are better in health facilities and consequently better equipped and proactive in dealing with the pandemic. Hence investment in human capital is very much important and needed. Better education and health promote cleanliness, awareness and hygiene which improves the immunity of human beings and ultimately result in better and fewer chances of disease. It has been observed that the death rate is higher in the older population (Dowd et al. 2020) which is greater than 60 years so a better and targeted approach should be used about them and allow the younger population for the economic activity to run the cyclone of development.

\section{Ethical issues and considerations}

COVID-19 transmission and infection in the community have triggered collaborative efforts at the individual level, community level, institutional level, government level and intergovernmental levels. Technological giants and individuals are contributing to the data and its collection methods and in the development of analytical tools in order to understand the deep pattern of transmission and spread, demographic attribute's relationships with COVID-19 infections, relationship with medical health history, current location, movements of infected people. All this is being done through data collections systems such as websites and apps. Contact tracing apps such as the Arogya Setu app by the Indian Government, have been pushed to be installed for keeping safe the healthy person from the infected person by informing them of the rule-based quantified risk exposure in the surroundings of individuals. There are many individual efforts whose data validity and reliability are questioned. Contact tracing Apps are one of digital surveillance in the pandemic which needs proper protection of individual data and medical history and attributes from going in the hand of adversaries. In addition to this, in the 
Fig. 7 State wise map of COVID-19 infection cases. Dark color represents more COVID-19 cases and light color represents less number of cases (Mygov WHO 2020)

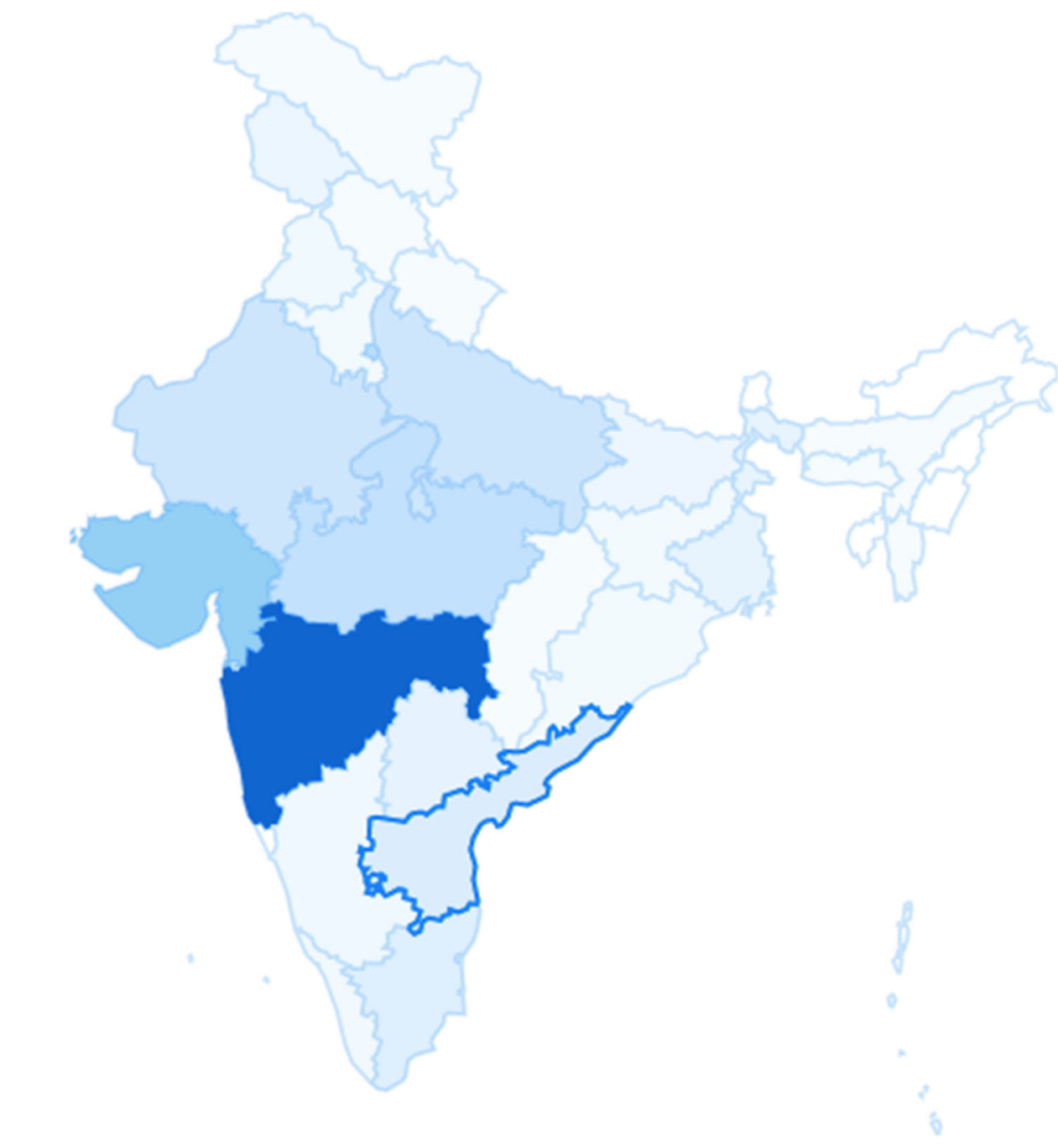

Active cases

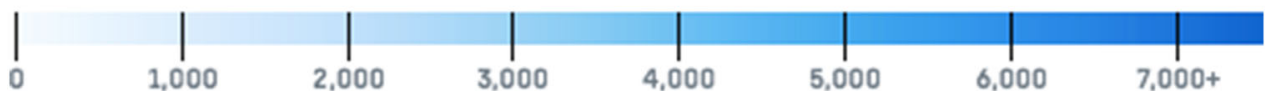

present circumstances as posed by COVID-19, the Digital technologies and analytics framework of prediction and data collection should include ethical data collection practices, consent taking steps in all their data collection methods and stages. Digital technology tools accessing data need to conform to the international guidelines of data collection and access and storage of information without compromising the security and privacy of individuals. Ethical practices related to data sharing should also be considered so that the community trusts the finding of the research work. There is a need for clarity of perspective on the rapidly evolving field of human data collection using digital tools. The ethical and legal boundaries of such tools for disease surveillance and contact tracing are unclear. This needs clarity, equitable and egalitarian policies for the stakeholders.

\section{Conclusion}

This proposed research work has done extensive analysis of the information related to Indian states and UTs and their adopted measures and strategies and outcome of those strategies. Results and discussion shows that States with higher education and better health services and proactive leadership are performing better in mitigation and containment of COVID-19 spread. States with more industrialised economies and labour in or out from the other states are lagging behind and suffering more from COVID-19. States with better law and order with stringent rules and regulation and their execution are also doing better. Geologically different terrain states are also in a better position to handle the COVID-19 situation. There is a need to learn from better-performing states and more focus should be 
given to testing rate and improving health services in states. Additionally, data collection and disease surveillance tools should be ethically and legally conforming to the guidelines and framework of the international community and stakeholders.

\section{References}

Ai T, Yang Z, Hou H, Zhan C, Chen C, Lv W, Tao Q, Sun Z, Xia L (2019) Correlation of chest CT and RT-PCR testing in coronavirus disease 2019 (COVID-19) in China: a report of 1014 cases. Radiology 296:200642

Alhazzani W, Møller MH, Arabi YM, Loeb M, Gong MN, Fan E, Oczkowski S, Levy MM, Derde L, Dzierba A (2019) Surviving sepsis campaign: guidelines on the management of critically ill adults with coronavirus disease 2019 (COVID-19). Intensive Care Med 46(1-34):2020

Arentz M, Yim E, Klaff L, Lokhandwala S, Riedo FX, Chong M, Lee M (2020) Characteristics and outcomes of 21 critically ill patients with COVID-19 in Washington state. Jama 323:1612-1614

Cascella M, Rajnik M, Cuomo A, Dulebohn SC, Di Napoli R (2020) Features, evaluation and treatment coronavirus (COVID-19). In: Statpearls [internet]. StatPearls Publishing

Cohen J, Kupferschmidt K (2020) Countries test tactics in 'war' against covid-19

de Paz C, Muller M, Maria Munoz Boudet A, Gaddis I (2020). Gender dimensions of the COVID-19 pandemic

Del Rio C, Malani PN (2020) Covid-19-new insights on a rapidly changing epidemic. Jama 323:1339-1340

Dong J, Zhou Y, Zhang Y, Franz D (2020) A validation study for the successful isolation policy in china: a meta-analysis in COVID19. medRxiv

Dowd JB, Andriano L, Brazel DM, Rotondi V, Block P, Ding X, Liu Y, Mills MC (2020) Demographic science aids in understanding the spread and fatality rates of COVID-19. Proc Natl Acad Sci 117(18):9696-9698

Emanuel EJ, Persad G, Upshur R, Thome B, Parker M, Glickman A, Zhang C, Boyle C, Smith M, Phillips JP (2020) Fair allocation of scarce medical resources in the time of COVID-19

Fernandes N (2020) Economic effects of coronavirus outbreak (COVID-19) on the world economy. Available at SSRN 3557504

Gabay G, Bellissimo N, Garby I, Zemel G, Gere A, Moskowitz HR, et al (2020) Driving public compliance with the health policy of social distancing: the case of the COVID-19 pandemic in India

Gilbert M, Pullano G, Pinotti F, Valdano E, Poletto C, Boëlle P-Y, d'Ortenzio E, Yazdanpanah Y, Paul Eholie S, Altmann M et al (2020) Preparedness and vulnerability of African countries against importations of COVID-19: a modelling study. The Lancet 395(10227):871-877

Hui David S, Azhar Esam I, Madani Tariq A, Ntoumi F, Kock R, Dar O, Ippolito G, Mchugh Timothy D, Memish Ziad A, Drosten C et al (2019) The continuing 2019-ncov epidemic threat of novel coronaviruses to global health-the latest novel coronavirus outbreak in Wuhan, China. Int J Infect Dis 91(264):2020

IANS (2020) India's covid testing rate is low, says who chief scientist. The Times of India

Khajanchi S, Sarkar K (2020) Forecasting the daily and cumulative number of cases for the COVID-19 pandemic in India. Chaos Interdiscip J Nonlinear Sci 30(7):071101
Khajanchi S, Sarkar K, Mondal J, Perc M (2020) Dynamics of the COVID-19 pandemic in India. arXiv:2005.06286

Kumar S, Kalia A, Sharma A (2017) Predictive analysis of alertness related features for driver drowsiness detection. In: International conference on intelligent systems design and applications. Springer, pp 368-377

Kumar S, Saibal Pal K, Singh R (2018a) A novel method based on extreme learning machine to predict heating and cooling load through design and structural attributes. Energy Build 176:275-286

Kumar S, Pal SK, Singh RP (2018b) A conceptual architectural design for intelligent health information system: case study on India. In: Quality, IT and Business Operations. Springer, pp 1-15

Kumar S, Pal SK, Singh R (2019) A novel hybrid model based on particle swarm optimisation and extreme learning machine for short-term temperature prediction using ambient sensors. Sustain Cities Soc

Loayza NV, Pennings S (2020) Macroeconomic policy in the time of COVID-19: a primer for developing countries

Mathur AN (2020), Strategies for solving wicked problems of true uncertainty: tackling pandemics like covid-19 (version: April 13, et al (2020) Technical report. Research and Publication Department, Indian Institute of Management Ahmedabad, p 2020

Mhlanga D, Ndhlovu E (2020) Socio-economic implications of the COVID-19 pandemic on smallholder livelihoods in Zimbabwe

Mihailov A et al (2020) Quantifying the macroeconomic effects of the COVID-19 lockdown: Comparative simulations of the estimated galí-smets-wouters model. Technical report, Henley Business School, Reading University

Mygov WHO, John Hopkins University (2020) Data sources for COVID-19

Paquet M, Schertzer R (2020) Covid-19 as a complex intergovernmental problem. Can J Polit Sci 53:1-5

Rajagopalan S, Choutagunta A (2020) Assessing healthcare capacity in India

Rodriguez-Morales AJ, Gallego V, Escalera-Antezana JP, Mendez CA, Zambrano LI, Franco-Paredes C, Suárez JA, RodriguezEnciso HD, Balbin-Ramon GJ, Savio-Larriera E et al (2020) Covid-19 in Latin America: the implications of the first confirmed case in Brazil. Travel Med Infect Dis

Sarkar K, Khajanchi S, Nieto JJ (2020) A mathematical model for COVID-19 transmission dynamics with a case study of India. Chaos Solitons Fract 140:110173

Kankan S, Subhas K, Nieto Juan J (2020) Modeling and forecasting the COVID-19 pandemic in India. Chaos Solitons Fract 139:110049

Sharma S, Zhang M, Gao J, Zhang H, Kota SH et al (2020) Effect of restricted emissions during COVID-19 on air quality in India. Sci Total Environ 728:138878

Shekhar S. A quantitative framework for expanding testing capacity of COVID-19 in India

Shivendu S, Chakraborty S, Onuchowska A, Patidar A, Srivastava A (2020) Is there evidence that BCG vaccination has non-specific protective effects for COVID-19 infections or is it an illusion created by lack of testing? Available at SSRN 3579847

Singh R, Adhikari R (2020) Age-structured impact of social distancing on the COVID-19 epidemic in India. arXiv:2003. 12055

Sinha S, Sinha N (2020) Modelling of covid-19 infection propagation data in Indian population

Venkateswaran J, Damani O (2020) Effectiveness of testing, tracing, social distancing and hygiene in tackling COVID-19 in India: a system dynamics model. arXiv:2004.08859

Vijayaraghavan P, Singhal D (2020) A descriptive study of indian general public's psychological responses during COVID-19 pandemic lockdown period in India 
Wang CJ, Ng CY, Brook RH (2020) Response to COVID-19 in Taiwan: big data analytics, new technology, and proactive testing. Jama 323:1341-1342

Wang J, Tang K, Feng K, Lv W. When is the COVID-19 pandemic over? Evidence from the stay-at-home policy execution in 106 Chinese cities
World Health Organization et al (2020) Who director-general's opening remarks at the media briefing on COVID-19-11 March 2020. Geneva, Switzerland

Publisher's Note Springer Nature remains neutral with regard to jurisdictional claims in published maps and institutional affiliations. 